\title{
Efficacy of Multiple Isocentric Volumetric Modulated Arc Therapy (VMAT) for Treatment of Bilateral Breast Carcinoma
}

\author{
Rathore VB ${ }^{1}$, Chandrakar PK $^{2}$, Choudhary $\mathbf{V}^{3}$, Azad SK ${ }^{4}$, Kerketta $\mathbf{M}^{5}$ \\ ${ }^{1}$ Dr. Vikram Bali Rathore, Ph D, Assistant Professor. ${ }^{2}$ Dr. Pradeep Kumar Chandrakar, MD, Assistant Professor, ${ }^{3}$ Dr. \\ Vivek Choudhary, MD, Professor, ${ }^{4}$ Dr Surendra Kumar Azad, MD, Professor. ${ }^{5}$ Dr Manjula Kerketta, Assistant Professor. \\ All are affiliated to Department of Radiotherapy, Regional Cancer Centre, Pt. J.N.M. Medical College, Jail Road, Raipur, \\ Chhattisgarh, India.
}

Address for Correspondence: Dr. Vikram Bali Rathore, Email. rathorevb@rediffmail.com

\begin{abstract}
Treating bilateral breast cancer with radiotherapy by conventional techniques is difficult because it requires multiple field settings from different orientations resulting in hot and cold spots at field junctions. Planning with Volumetric Modulated Arc therapy gives uniformity in dose distribution, minimizing hot and cold spots resulting in high doses to target and minimum dose to normal tissues. Volumetric Modulated Arc Therapy (VMAT) has been done on a patient with bilateral breast Cancer with two isocentres and dual half arcs in each isocentre. Mean dose achieved to PTV (Planning Target Volume) was 50Gy. The values of Conformity index (CI) and Homogeneity index (HI) were found to be 1.2 and 1.9 respectively. Maximum doses to lung, liver and heart were found in the region close proximity to the target. VMAT is found to be better technique for treating bilateral breast cancer. Post radiotherapy follow up at two years showed complete control of both primaries without any systemic recurrence and significant side effects.
\end{abstract}

Key words: Anisotropic Analytical Algorithm, Bilateral Breast Cancer, Progressive Resolution Optimizer, Volumetric Modulated Arc Therapy.

\section{Introduction}

Breast Cancer is the most common cancer in women worldwide. The incidence of this cancer is even high in developing countries [1-2]. In 2012 almost 145000 Indian women were diagnosed with breast cancer, since 2009 it became the most frequently diagnosed form of neoplastic disease in women in India and is now the most common cause of cancer deaths in country [3]. The usage of radiation dose delivery to chest wall after total mastectomy, as well as the treatment of conservative breast remains complex. In the conventional breast or chest wall irradiation technique, the beam arrangement consists of two opposing tangential glancing portals [4], which allows acceptable coverage of the breast tissue while minimizing the dose to the adjacent critical structures (i.e. ipsilateral lung, contralateral breast and heart). Radiation toxicity in the treatment of breast cancer have shown that the effect on normal tissue can constitute a significant clinical

Manuscript received: $17^{\text {th }}$ May 2015

Reviewed: $5^{\text {th }}$ June 2015

Author Corrected: $14^{\text {th }}$ June 2015

Accepted for Publication: $26^{\text {th }}$ June 2015 problem, particularly increased cardiac mortality and this may offset any potential survival benefit of treatment [5-7]. Treating bilateral breast cancer with radiotherapy by conventional techniques is even more complex because it requires multiple field settings from different orientations resulting in hot and cold spots at field junctions. The development of IMRT has enabled the delivery of highly conformal dose distribution to the target along with higher sparing of critical normal tissues, which becomes important in sites where tumour are in close proximity of abutting critical normal structures [8]. Rapid Arc or Volumetric Modulated Arc Therapy is the advance form of IMRT, has been found to produce comparable conformal dose distribution and faster treatment delivery compared to conventional static IMRT [9]. In the present study, results of Radiotherapy of bilateral breast (both breast) Carcinoma with VMAT (Varian Medical System, Palo Alto, CA) technique with two isocentre and dual half arc in each isocentre has been discussed.

\section{Case Report}


A 53 years old female patient with infiltrating duct carcinoma in both breasts was taken for radiotherapy. Patient had under gone Modified Radical Mastectomy (MRM) for both breast and received 6 cycles of adjuvant chemotherapy, and then planned for adjuvant radiation therapy to both breasts. Simulation Computed tomography (CT) images were obtained from neck region to lower abdomen on Brilliance Big Bore CT simulator (Phillips Medical Systems, USA) in $3 \mathrm{~mm}$ slices. All in One whole body base plate with thermoplastic immobilization was used. Target volume (Chest wall) and critical structures (Lung, Heart, Spinal cord, liver and Oesophagus) were delineated. VMAT plan with two isocentre and dual half arc in each isocentre were generated using Eclipse treatment planning system (Version 10.0), for $6 \mathrm{MV}$ photon beams in Varian Clinac DHX with 120 leafs millennium MLC. The beam arrangements and dose distributions were shown in figure-1. The Progressive Resolution Optimizer (PRO 3) was used to optimize (to achieve clinical goal/dose constraints) VMAT plan. Volume dose was calculated with Anisotropic Analytical Algorithm (AAA version-10.028). Total dose (50Gy) was delivered 25 fractions, 5 days per week in 37 days (during June-July 2013).

\section{Discussions}

Prescribed dose to PTV was 50Gy in 25 fractions. Dose to PTV was found to vary from 28.7 Gy near the body surface to 57.08 Gy with mean dose of 50Gy. The values of $\mathrm{CI}$ and $\mathrm{HI}$ were found to be 1.2 and 1.9 respectively. Where $\mathrm{CI}$ is defined as $\mathrm{CI}=\mathrm{V}_{\mathrm{PTV}} \mathrm{x}$ $\mathrm{V}_{\mathrm{TV}} / \mathrm{TV}_{\mathrm{PV}}{ }^{2}$ where $\mathrm{V}_{\mathrm{TV}}$ is the treatment volume of prescribed isodose lines, $\mathrm{V}_{\mathrm{PTV}}$ is the volume of PTV and $\mathrm{TV}_{\mathrm{PV}}$ is the volume of $\mathrm{V}_{\mathrm{PTV}}$ within $\mathrm{V}_{\mathrm{TV}}$. Similarly $\mathrm{HI}$ is defined as $\mathrm{HI}=\mathrm{D}_{5} / \mathrm{D}_{95}$, where $\mathrm{D}_{5}$ and $\mathrm{D}_{95}$ are the minimum dose delivered to $5 \%$ and $95 \%$ volume of PTV. The minimum dose to the PTV was found in the region near to body surface. It may be due to the skin sparing effect of Mega Volt photon beam. The maximum dose, $114.2 \%$ of prescription (point dose), was found in the region near posterior end of left chest wall inside PTV. It may be due to tissue inhomogeneity and irregular body surface. Doses to critical organs are listed in table-1. The higher doses to Lung, Liver and heart were found in the region close proximity to PTV.

Table-1: Optimized dose to critical organs in Gray (Gy)

\begin{tabular}{|l|l|l|l|l|l|}
\hline S.N. & Organ & Objective & Max. dose & Min. dose & Mean dose \\
\hline 1. & Lung & Mean $<20 \mathrm{~Gy}$ & $55.0 \mathrm{~Gy}$ & $1.6 \mathrm{~Gy}$ & $23.8 \mathrm{~Gy}$ \\
\hline 2. & Heart & V67\% $<45 \mathrm{~Gy}$ & $55.0 \mathrm{~Gy}$ & $5.1 \mathrm{~Gy}$ & $25.1 \mathrm{~Gy}$ \\
\hline 3. & Spinal Cord & Max. $<45 \mathrm{~Gy}$ & $17.1 \mathrm{~Gy}$ & $2.5 \mathrm{~Gy}$ & $08.8 \mathrm{~Gy}$ \\
\hline 4. & Liver & V50\% $<35 \mathrm{~Gy}$ & $54.5 \mathrm{~Gy}$ & $1.3 \mathrm{~Gy}$ & $01.7 \mathrm{~Gy}$ \\
\hline 5. & Esophagus & V33\% $<45 \mathrm{~Gy}$ & $22.8 \mathrm{~Gy}$ & $5.1 \mathrm{~Gy}$ & $03.9 \mathrm{~Gy}$ \\
\hline
\end{tabular}

Figure-1: Beam arrangements and dose distributions of two isocentre and dual half arc treatment plan.

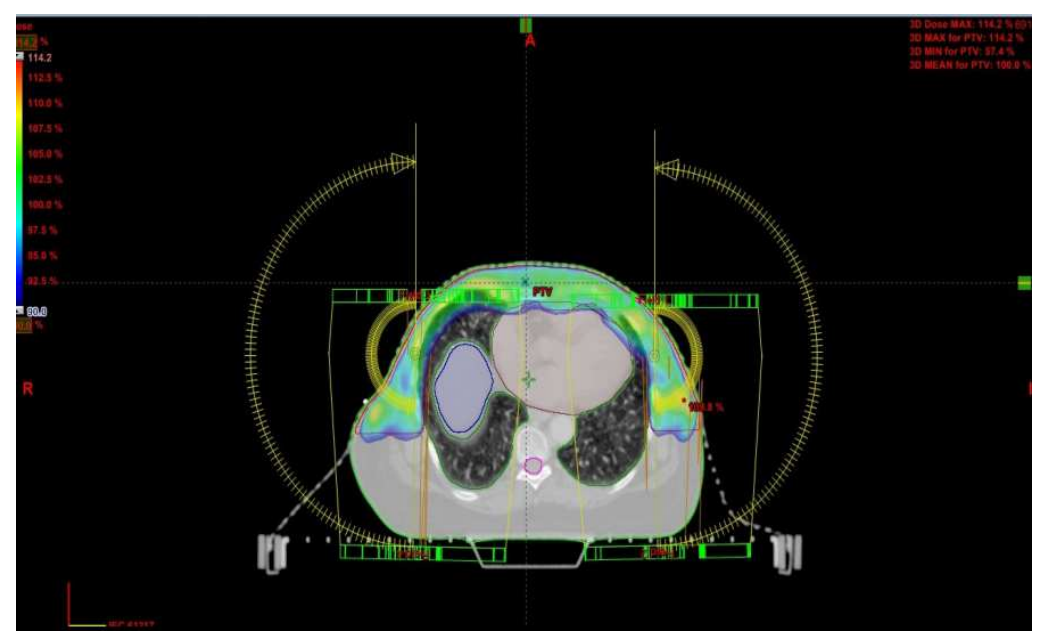




\section{Conclusions}

VMAT is found to be better technique for treating bilateral breast cancer. Post radiotherapy follow up at two years showed complete control of both primaries without any systemic recurrence and significant side effects.

\section{Acknowledgements}

The authors would like to thanks Dr. A. K. Chandrakar, Dean, Pt. J.N.M. Medical College, Raipur, for his continuous encouragement and support for this study.

\section{References}

1. Boyle P, Howel A, The globalisation of breast cancer. Breast Cancer Res. 2010 Dec 20;12 Suppl 4:S7. doi: $10.1186 / \mathrm{bcr} 2736$.

2. Akarolo Anthony SN, Ogundiran TO, Adebamowo CA, Emerging breast cancer epidemic: Evidence from Africa. Breast Cancer Res. 2010 Dec 20;12 Suppl 4:S8. doi: $10.1186 /$ bcr 2737 .

3. Mallath MK et al. Cancer burden and health system in India, The growing burden of cancer in India: Epidemiology and social context. The Lancet Oncology 2014;15[6]:e205-212. doi.org/10.1016/S14702045(14)70115-9.

4. Recht A, Breast Cancer: Stages $\mathrm{T} 1$ and $\mathrm{T} 2 \mathrm{ln}$ : Gunderson LL, Tepper JE editors $2^{\text {nd }}$ ed. Clinical Radiation Oncology. Elsevier Publication. Churchill Livingstone 2007: 1475-1495.
5. Cuzick J, Stewart H, Rutavist L, Houghton J, Edwards R, Redmand C, et al. Cause specific mortality in long-term survivors of breast cancer who participated in trails of Radiotherapy. J Clin Oncol. 1994 Mar;12(3):447-53.

6. Gagliardi G, Lax I, Ottolenghi A, Rutqvist LE. Long term cardiac mortality after radiotherapy of breast cancer -application of the relative seriality model. Br J Radiol. 1996 Sep;69(825):839-46.

7. Rutqvist LE, Lax I, Fomander T, Johansson $\mathrm{H}$. Cardiovascular mortality in a randomized trial of adjuvant radiation therapy versus surgery alone in primary breast cancer. Int $\mathbf{J}$ Radiat Oncol Biol Phys. 1992;22(5):887-96.

8. Intensity modulated radiotherapy collaborative working group. Intensity Modulated Radiotherapy: Current status and issues of interest. Int.J. Radiat. Oncol. Biol. Phys.2001Nov.15; 51(4): 880914.doi.org/10.1016/S0360-3016(01)01749-7.

9. Popescu CC, Olivotto IA, Beckham WA et al., Volumetric modulated arc therapy improves dosimetry and reduces treatment time compared to conventional intensity-modulated radiotherapy for locoregional radiotherapy of left -side breast cancer and internal mammary nodes. Int. J. Radiat. Oncl. Biol.Phys. 2010 Jan; 76(1):287-295. doi.org/10.1016/j.ijrobp.2009.05.038.

\section{How to cite this article?}

Rathore VB, Chandrakar PK, Choudhary V, Azad SK, Kerketta M. Efficacy of Multiple Isocentric Volumetric Modulated Arc Therapy (VMAT) for Treatment of Bilateral Breast Carcinoma. Int J Med Res Rev 2015;3(5):535-537. doi: 10.17511/ijmrr.2015.i5.101. 